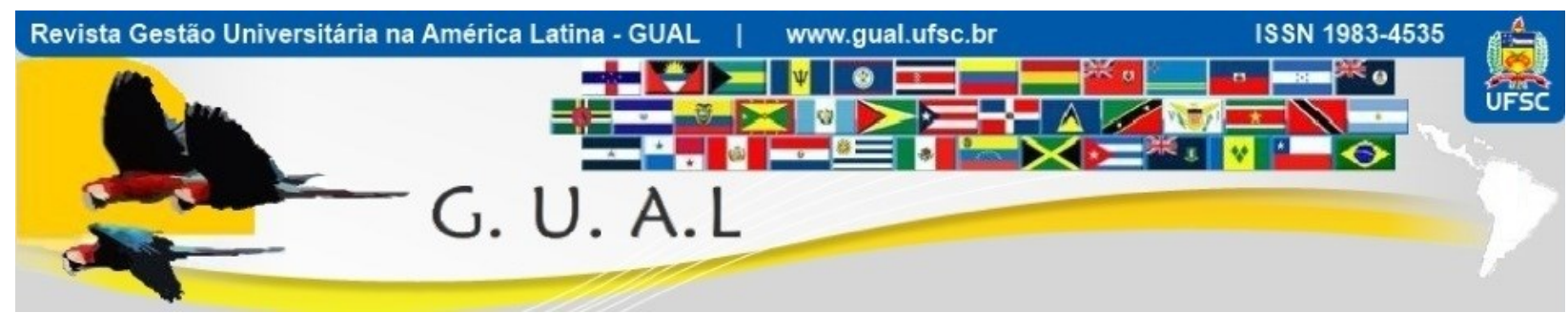

DOI: http://dx.doi.org/10.5007/1983-4535.2018v11n1p276

\title{
ABORDAGEM CRÍTICA SOB A ÓTICA DA AÇÃO COMUNICATIVA DE HABERMAS: GESTÃO PARTICIPATIVA NO CAMPUS SERRA DO IFES
}

\author{
CRITICAL APPROACH UNDER THE OPTICS OF HABERMAS'S \\ COMMUNICATIVE ACTION: PARTICIPATIVE MANAGEMENT IN CAMPUS \\ SERRA OF THE IFES
}

Eglalciane Lyrio Tongo Castro, Mestre Universidade Federal do Espírito Santo - UFES eglalciane@gmail.com

Ricardo Roberto Behr, Doutor Universidade Federal do Espírito Santo - UFES rrbehr@gmail.com

Recebido em 19/maio/2016

Aprovado em 18/setembro/2017

Sistema de Avaliação: Double Blind Review

Esta obra está sob uma Licença Creative Commons Atribuição-Uso. 


\title{
RESUMO
}

O estudo tem como objetivo compreender, de forma crítica, como se caracteriza a prática da gestão participativa no campus Serra do Ifes, a partir a partir do entendimento e do processo interativo dos servidores Técnico-administrativos (TAE) das classes C, D e E e das chefias imediatas. Para tanto, a Teoria da Ação Comunicativa - TAC de Jürgen Habermas, bem como sua proposta de democracia deliberativa foram empreendidas como marco teórico para compreensão desse processo. Esse trabalho caracteriza-se como uma pesquisa de abordagem qualitativa. Os dados empíricos foram produzidos por meio de pesquisa documental, observação participante e entrevistas semiestruturadas. Utilizou-se a análise de conteúdo para o tratamento das informações obtidas nas entrevistas. Os resultados indicam que a prática da gestão participativa caracteriza-se como um espaço estratégico para alcance do êxito e não do entendimento, onde os TAE são corresponsáveis no processo de manutenção e construção dos fenômenos que emperram o desenvolvimento de uma participação democrática.

Palavras-chave: Administração Pública. Participação. Prática de Gestão Participativa. Teoria da Ação Comunicativa.

\begin{abstract}
This study aimed to understand, critically, as is characterized the participative management on IFES - Campus Serra, from the understanding and the interactive process of the administrative technicians staff (TAEs) classes C, D and E and immediate supervisors. Thus, Jürgen Habermas's Communicative Action Theory (CAT), as well as its proposal for democracy deliberative, were undertaken as a theoretical framework for understanding this process. This work is characterized as a qualitative research and has a critical approach with dialectical view of social reality. Empirical data were produced by desk research, participant observation and semi-structured interviews. The content analysis was used for the treatment of interview. The results point to the construction of participatory actions of instrumental nature, established based on the interests of the management of specific and individual groups. Thus, the practice of participative management is characterized as a strategic space to reach the success and not the understanding, where the TAEs share the responsibility in the process of maintenance and construction of the phenomena that hamper the development of democratic participation.
\end{abstract}

Keywords: Public Administration. Practice Participatory Management. Managerial Reform. Communicative Action Theory. 


\section{INTRODUÇÃO}

A absorção de ideias e práticas da gestão empresarial por parte do Estado, desenvolvidas principalmente durante o governo de Fernando Henrique Cardoso (FHC), repercutiu de forma substancial na forma de organização, financiamento e gestão dos sistemas de ensino técnico-profissional no Brasil. No âmbito do Instituto Federal do Espírito Santo (Ifes), dentro da lógica gerencialista, a participação do servidor ligado à área administrativa passa a ser redefinida a partir das diretrizes da Lei $n^{0}$ 8.112/1990, a qual instituiu a Avaliação de Desempenho como parâmetro para o servidor concursado adquirir estabilidade.

Nos governos seguintes ocorre ao aperfeiçoamento dessas práticas e a implementação dos modelos de gestão participativa na administração pública ganha espaço como proposta performativa constituindo a flexibilização dos processos e a ruptura com a burocratização (PAES DE PAULA, 2005).

De acordo com Faria (2009) as críticas à participação dos trabalhadores nas unidades produtivas indicam que as formas de participação na gestão representam estratégia para aumentar a produtividade e comprometimento por parte dos trabalhadores. Faria (2009) propondo uma visão mais ampla, além dos processos gerenciais com foco na produtividade, busca apresentar as contradições existentes na expansão da gestão participativa para as esferas das organizações. Segundo o autor, a participação dos trabalhadores na gestão pode significar comprometimento com o desempenho e reforço do sistema capitalista, caracterizando-se como participação instrumental, bem como pode constituir resistência dos trabalhadores organizados às formas de dominação e controle em busca de uma participação democrática (FARIA, 2009, p. 76). É nessa linha analítica de duplo efeito que a gestão participativa se insere no cerne dessa pesquisa.

Nesse âmbito, o uso da Teoria da Ação Comunicativa (TAC) na área das organizações tem sido empreendido no sentido de questionar o modelo burocrático de gestão e organização, bem como de propor alternativas mais adequadas aos critérios considerados pela abordagem comunicativa (AGUIAR, 2011). Habermas (2002), ao questionar a ação instrumental como forma de agir orientado para o êxito, propõe a ação comunicativa como uma via alternativa que permite o entendimento mútuo e a tomada de decisão num processo democrático.

Entende-se que as dicussões de Habermas estão voltadas para a práxis social, para a transparência nas relações sociais e para a capacidade de argumentação, por meio da linguagem dos atores envolvidos nessa relação (FREITAG, 1990). Todavia, as contribuições 
da TAC oferecem um quadro analítico para discussões sobre tomada de decisão em organizações.

Assim sendo, o objetivo desse estudo é compreender, de forma crítica, como se caracteriza a prática da gestão participativa no campus Serra do Ifes, a partir do entendimento e do processo interativo dos servidores Técnico-administrativos em Educação (TAE) das classes C, D e E e das chefias imediatas. Para tanto, a Teoria da Ação Comunicativa (TAC) de Jürgen Habermas, bem como a sua proposta de democracia deliberativa são empreendidas como marco teórico para compreensão desse processo.

Como afirma Paes de Paula (2005) há um interesse maior em investigações com ênfase na gestão empresarial em detrimento da gestão pública. Além disso, as discussões sobre a estruturação burocrática, principalmente no que se refere às suas disfunções, são pautadas, em grande parte, na teoria administrativa (PAES DE PAULA, 2005). Desse modo, a lente crítica da TAC constitui uma alternativa explicativa dos fenômenos interativos organizacionais, suprindo as limitações da teoria funcionalista (VIZEU, 2005). A TAC traz contribuições para o entendimento do processo de negociação entre trabalhadores no âmbito da Administração Pública onde "[...] a estrutura burocrática atua mais sutilmente como mecanismo de dominação e limitação do sujeito" (VIZEU, 2003, p. 6).

A prática da gestão participativa, enquanto cenário para discussão, argumentação e tomada de decisão, constitui espaço conveniente para o desenvolvimento de contradições. Desse modo, a problemática levantada justifica e oferece relevância a este artigo, o qual está voltado para a seguinte questão de pesquisa: como se caracteriza a prática da gestão participativa no campus Serra do Ifes, a partir do entendimento e do processo interativo dos servidores Técnico-administrativos em Educação (TAE) das classes C, D e E e das chefias imediatas?

\section{REFERENCIAL TEÓRICO}

\subsection{PARTICIPAÇÃO}

Para Motta (1983), a participação é um conceito ambíguo e o seu significado reflete o contexto específico em que se desenvolve. No âmbito da gestão, a participação refere-se a uma proximidade com o poder e a preocupação com o tema surge com a impossibilidade de administrar o conflito apenas pela coação física (Motta, 1983). 


\section{ABORDAGEM CRÍTICA SOB A ÓTICA DA AÇÃO COMUNICATIVA DE HABERMAS: GESTÃO \\ PARTICIPATIVA NO CAMPUS SERRA DO IFES \\ DOI: http://dx.doi.org/10.5007/1983-4535.2018v11n1p276}

O conceito de participação adotado nessa pesquisa refere-se ao caráter emancipatório e ao seu valor intrínseco para realização do indivíduo e da coletividade. Com isso, afasta-se de teorias participacionistas que consideram a participação apenas como um meio para alcançar resultados (STRECK; ADAMS, 2006). De acordo com Demo (1993) a participação não deve ser concedida, e sim conquistada, construída, é um processo infindável. A participação não é um instrumento para a tomada do poder, mas outra forma de poder (DEMO, 1993).

Assim sendo, esse estudo segue a orientação de participação tal como na proposta de democracia deliberativa de Habermas (1997), na medida em que se constitui como espaço político, intersubjetivo, autônomo e constituído por atores em iguais condições de argumentação num contexto de interações simples, livre de qualquer diferenciação de papéis e funções.

Não obstante, a avaliação da participação dos trabalhadores no âmbito organizacional precisa dar conta dos níveis, dos limites e possibilidades que se constituem no interior das organizações, pois esses elementos evidenciam a finalidade para qual a organização foi criada. Ao mesmo tempo, buscar compreender os estímulos pelos quais os trabalhadores se envolvem na gestão da máquina produtiva pode servir de apoio para a descoberta de processos que mantém ou modificam um modelo de vida organizacional (FARIA, 2009).

\subsection{PRÍNCIPIOS NORTEADORES DA TEORIA DA AÇÃO COMUNICATIVA DE JÜRGEN HABERMAS}

A ação comunicativa de Habermas (2012, v. 1 e 2) vai além da crítica ideológica tradicional, ou seja, desloca a "práxis do trabalho" do centro da constituição da razão emancipatória. Para Habermas, a categoria "trabalho" apresenta equívocos ao ser concebida enquanto "[...] substrato material e universal da constituição da razão" (FREITAG, 1990, p. 110). Segundo ele, a questão está no fato da categoria "trabalho" limitar-se à concepção de racionalidade instrumental, por isso, não pode ser concebida como cerne da ação humana (HABERMAS, 2012, v. 1 e 2).

Habermas (2012, v. 1 e 2) propõe uma nova mediação para a emancipação com vistas a superar esse impasse: a intersubjetividade. Nesse novo paradigma a razão, enquanto consciência, afasta-se do centro da compreensão da ação humana e a comunicação passa a ter o papel principal como base ordenadora da vida em sociedade (VIZEU, 2005). Habermas sugere o retorno da razão instrumental às fábricas e aos escritórios da administração burocrática, sob o controle da maioria, num processo consensual e transparente (FREITAG, 
1990, p.151). Nessa linha, ocorreria a primazia da razão comunicativa sobre a razão instrumental, redefinindo espaços de argumentação, por meio de processos reflexivos de discussão dos problemas e das suas soluções. Habermas (2012, v. 1 e 2), portanto, não descarta a existência da razão instrumental, mas defende o papel secundário que essa deve assumir nas ações humanas em sociedade.

Para Habermas (2002, p. 81) a racionalidade da ação ou ação instrumental “[...] se limita aos padrões aceitos - à consistência lógica, aos princípios gerais da ação orientada para o sucesso e ao asseguramento da evidência empírica". Nesse sentido, o paradigma comunicativo ou da linguagem supera esse pensamento na medida em que propõe a desnaturalização da realidade por meio da crítica aos padrões aceitos.

Das análises de Habermas sobre as limitações da racionalidade instrumental surge outro tipo de ação, a ação comunicativa orientada para o entendimento linguístico. Habermas (1989, p. 79, 2012, v. 1 e 2) conceitua a ação comunicativa como processo mediado pelo entendimento linguístico, cuja premissa é o reconhecimento, entre os indivíduos envolvidos, sobre algo, num processo de argumentação onde a única forma de coação é a razão. A Teoria da Ação Comunicativa pode ser compreendida a partir da seguinte afirmação de Habermas:

Chamo de comunicativa às interações nas quais as pessoas envolvidas se põem de acordo para coordenar seus planos de ação, o acordo em cada caso medindo-se pelo reconhecimento intersubjetivo das pretensões de validez (HABERMAS, 1989, p. 79).

Portanto, Habermas (2012, v. 1 e 2) organiza dois tipos básicos de ação racional: a ação racional estratégica, na qual a ação é orientada para o êxito, onde prevalece a relação sujeito-objeto e a ação racional comunicativa, que considera pelo menos dois agentes linguisticamente competentes. A base da racionalidade comunicativa é o uso de argumentos válidos, suscetíveis às pretensões de validez e o objetivo é o entendimento (VIZEU, 2003). Durante a problematização das pretensões de validez, para resolver os desacordos e dúvidas pode ocorrer a passagem da atividade orientada para o entendimento para a ação estratégica ou ainda o abandono da comunicação (AGUIAR, 2011, p. 24).

A ideia central desse projeto está na possibilidade de construção de uma práxis social voltada para o entendimento que questione o domínio econômico e burocrático em esferas do mundo da vida (objetivo, subjetivo e social), o qual pode levar à perda da liberdade. Isso afasta a práxis do trabalho como categoria de análise da ação humana. Habermas em sua 


\section{ABORDAGEM CRÍTICA SOB A ÓTICA DA AÇÃO COMUNICATIVA DE HABERMAS: GESTÃO \\ PARTICIPATIVA NO CAMPUS SERRA DO IFES \\ DOI: http://dx.doi.org/10.5007/1983-4535.2018v11n1p276}

Teoria da Ação Comunicativa parte do pressuposto de que a interação comunicativa se coloca no centro da ação social, onde os participantes, por meio da linguagem e num processo de negociação, buscam coordenar suas ações pela via do entendimento (VIZEU, 2005).

Nesse processo de interação entre pessoas, o ideal de fala ou estrutura do ato de fala constitui a base dos critérios de validade da ação comunicativa, visto que permite o acesso indireto à subjetividade. Essa validação pressupõe crítica ao discurso por meio de quatro pretensões de validade: (1) verdade - como totalidade dos fatos existentes; (2) correção como totalidade das relações interpessoais que são legitimamente reguladas pelo grupo; (3) sinceridade - como totalidade das vivências, em que apenas o locutor tem acesso; e (4) inteligibilidade - faz alusão à correção da expressão linguística para entendimento pelos demais participantes da ação comunicativa. Cada um desses parâmetros serviria para apontamento das distorções que poderiam surgir durante o processo de negociação.

Habermas (2012, v. 1 e 2) utiliza a distinção dos atos de fala proposta por Austin (1995), para explicar as distorções causadas pelos usos manipulativos da linguagem: com o ato ilocucionário a oração é fixada no seu significado e reflete o que o falante está pensando, no ato perlocucionário o falante objetiva causar um efeito sobre um ouvinte.

Nas ações estratégicas, as pretensões de validez são substituídas pelas pretensões de poder (HABERMAS, 2012, v. 2, p. 59). Na ação racional comunicativa, todos os participantes buscam seus fins ilocucionários orientados pelo entendimento linguístico. Se pelo menos um participante fizer uso da linguagem para fins perlocucionários tem-se, então, a ação estratégica.

\subsubsection{O mundo da vida e o sistema}

O conceito de mundo da vida aparece como complementar ao de ação comunicativa, entendido como contexto não problematizável e pano de fundo onde as interações com vistas a alcançar o entendimento se desenvolvem (HABERMAS, 2012, v. 2, p. 249). É o contexto onde o mundo objetivo dos fatos, o mundo social das normas e o mundo subjetivo das experiências internas se reproduzem por meio da ação comunicativa (AGUIAR, 2011).

A separação das dimensões mundo da vida e sistema contribui, sob o ponto de vista metodológico, para compreensão das sociedades modernas e torna possível a análise das estruturas, racionalidades e distorções contidas nessas duas dimensões da sociedade. A esse respeito, Aguiar (2011) ressalta que as duas dimensões se complementam, não sendo possível 


\section{ABORDAGEM CRÍTICA SOB A ÓTICA DA AÇÃO COMUNICATIVA DE HABERMAS: GESTÃO \\ PARTICIPATIVA NO CAMPUS SERRA DO IFES \\ DOI: http://dx.doi.org/10.5007/1983-4535.2018v11n1p276}

entender o movimento sociocultural sem compreender os sistemas sociais que o estruturam. Ao mesmo tempo não se pode entender a lógica dos sistemas sem conhecer os estímulos que ordenam as ações dos agentes sociais (AGUIAR, 2011).

Habermas (1987), ao propor essa visão dual e complementar da sociedade, problematiza o desenvolvimento das sociedades modernas com a racionalização do mundo da vida e com a criação de modelos de socialização que forçam a individualização. Nas sociedades atuais, onde predomina o capitalismo, a limitação da ação comunicativa à estrutura "natural", denominada mundo da vida, permite que o sistema seja coordenado pelos mecanismos dinheiro e poder em substituição à linguagem (AGUIAR, 2011). Em Habermas, essa invasão dos mecanismos sistêmicos no mundo da vida é denominada colonização do mundo da vida.

O predomínio dos mecanismos dos sistemas funcionais acaba transformando as formas de integração, mesmo em esferas de ação opostas à mudança para os meios dinheiro e poder, como educação e cultura (HABERMAS, 1987). Segundo Vizeu (2005), a colonização do mundo da vida ocorre de forma mais intensa em organizações produtivas e burocráticas, onde o dinheiro e o poder não podem forçar a solidariedade senão pela domesticação.

No que se refere à colonização do mundo da vida, o Estado assume um novo papel intervencionista. A capacidade de planejamento das administrações públicas passa a ser orientada pela racionalidade instrumental e as decisões são tomadas em detrimento da dimensão sociopolítica, deixando de considerar o interesse coletivo. Assim, os espaços privilegiados para a razão comunicativa, como o campo da educação, deixam de funcionar segundo o princípio da verdade, normatividade e expressividade, passando a funcionar de acordo com os princípios do dinheiro e do poder (FREITAG, 1993). Ocorre o aperfeiçoamento de uma cultura de especialistas e a destruição das faculdades críticas (HABERMAS, 1990, p. 162). No âmbito da atuação do Estado é possível perceber as consequências da colonização em via a conversão dos cidadãos em clientes e a inserção de práticas gerencialistas na administração pública.

O "remédio" para estas patologias sociais proposto por Habermas remete ao "reacoplamento" entre o sistema e o mundo da vida, por via da inserção de maior transparência, flexibilidade e participação nos assuntos de interesse coletivo (FREITAG, 1993). A “descolonização" deve ocorrer para permitir a primazia da razão comunicativa sobre a razão instrumental, redefinindo espaços de argumentação, por meio de processos reflexivos 
de discussão dos problemas e das suas soluções. A proposta de Habermas é de que a ação comunicativa flua entre o mundo da vida (sociocultural) e os sistemas, de maneira a alcançar tanto eficácia quanto a responsabilização dos participantes em relação às decisões tomadas (PINTO, 1994).

\title{
2.3 DEMOCRACIA DELIBERATIVA E ESFERA PÚBLICA
}

Ao apresentar a proposta alternativa de democracia deliberativa aos modelos liberal e republicano, Habermas (2006, p. 6, tradução nossa) conceitua:

\begin{abstract}
A deliberação é uma forma de comunicação exigente, ainda que se desenvolva a partir de rotinas diárias invisíveis nas quais as pessoas trocam razões umas com as outras. No curso das práticas cotidianas, os atores estão sempre expostos a um espaço de razões. Eles não podem fazer outra coisa, senão oferecer mutuamente demandas de validade para seus proferimentos e argumentos, uma vez que o que dizem deveria ser assumido - e, se necessário, provado - como algo verdadeiro, correto ou sincero e, sem dúvida, racional. Uma referência implícita ao discurso racional - ou à competição por melhores razões - é construída dentro da ação comunicativa como uma alternativa onipresente ao comportamento rotineiro.
\end{abstract}

A democracia deliberativa Habermasiana é "[...] procedimental, consiste numa possibilidade de diálogo normativo como argumentação e justificação que acontecem em espaços públicos autônomos, constituído por meio da linguagem e com base no direito" (AGUIAR, 2011, p. 35). Na visão de Habermas (1989, p. 92): “[...] uma norma que passa a vigorar essa via pode-se chamar 'justificada' porque a decisão alcançada argumentativamente indica que ela merece o predicado "igualmente boa para cada um dos concernidos"”.

Segundo Paes de Paula (2005b), a visão participativa da democracia, que emergiu nos anos 1960, vem sendo atualizada pela concepção de democracia deliberativa, fundamentada, principalmente, nas contribuições de Habermas. Para a autora, a democracia deliberativa, quando articulada com o conceito de esfera pública, supera os limites da democracia liberal, a qual equipara a dinâmica política ao jogo de mercado e que relega os cidadãos à apatia. $\mathrm{Na}$ visão de Habermas (1997, p. 92), a esfera pública:

[...] pode ser descrita como uma rede adequada para a comunicação de conteúdos, tomada de posição e opiniões; nela os fluxos comunicacionais são filtrados e sintetizados a ponto de se condensarem em opiniões públicas enfeixadas em temas específicos.

Assim sendo, a esfera pública representa um espaço social compartilhado, um local de aprendizagem que se reproduz pela ação comunicativa (AGUIAR, 2011). Constitui-se num 
espaço de mediação entre o Estado e a sociedade em torno do debate de temas oriundos do mundo da vida que em um dado momento se constitui num problema ou interesse da sociedade (HABERMAS, 1997).

Abrucio (1997) assevera que o conceito de esfera pública, como espaço de transparência e de aprendizado social deve estar presente, também, na organização interna da administração pública, sobretudo no momento de elaboração das políticas públicas e na execução do planejamento estratégico.

\section{METODOLOGIA}

Essa pesquisa faz parte de um estudo qualitativo mais amplo sobre a caracterização da prática da gestão participativa no campus Serra do Ifes e possui um enfoque crítico com visão dialética da realidade social, por buscar as causas e as consequências dos problemas e suas contradições (TRIVIÑOS, 1987, p. 125), sendo o objeto de estudo relacionado ao campo da administração pública.

A pesquisa foi realizada no campus Serra do Instituto Federal do Espírito Santo (Ifes) e a escolha desta instituição ocorreu devido ter iniciado, em 2013, a execução do Planejamento Estratégico e do Plano de Desenvolvimento Institucional do Ifes, em atendimento à Lei $\mathrm{n}^{\mathrm{o}}$ 11.892/08.

O Ifes é subdividido em 21 Campi, contudo, a pesquisa foi realizada no campus Serra, pois este estudo limitou-se a investigar um contexto específico visando o aprofundamento dos aspectos relativos a este contexto. Os sujeitos da pesquisa são os servidores técnicoadministrativos em educação e as chefias imediatas.

Para dar início a produção dos dados iniciais foi realizada uma pesquisa documental a fim de se conhecer as leis, decretos e documentos institucionais com indicativos que contribuíssem para a pesquisa. $\mathrm{O}$ acesso às informações se deu por meio do site institucional e documentos setoriais disponíveis no campus Serra. Além da pesquisa documental, optou-se pela observação participante e pela entrevista semiestruturada contendo perguntas abertas.

Os participantes da entrevista foram selecionados com base no critério da bola de neve. Segundo Baldin e Munhoz (2011), uma técnica não probabilística empregada em pesquisas sociais baseada na indicação por parte dos entrevistados de outros participantes. As entrevistas foram interrompidas quando as concepções, explicações e sentido atribuídos pelos sujeitos começaram a ter uma regularidade de apresentação (DESLANDES, 2007, p. 48). 
Quanto a caracterização dos entrevistados, TAE e chefias imediatas de ambos os sexos responderam às perguntas contidas no roteiro. Foram entrevistados oito TAE subordinados e 13 chefias imediatas.

Para tratamento das entrevistas foi utilizada a análise de conteúdo e conforme a técnica de categorização temática sugerida por Bardin (2011), as entrevistas foram transcritas, analisadas e classificadas dentro de categorias, não definidas à priori.

Tendo como premissas o referencial teórico da Teoria da Ação Comunicativa de Habermas, bem como a proposta conceitual de democracia deliberativa apresentada pelo autor, foram definidas quatro categorias principais nas falas dos TAE e das chefias imediatas: (1) Gestão Participativa: de que estamos falando?; (2) Participação e integração: cada um vai lá e defende o seu!; (3) Limites à Participação; e (4) A insatisfação com a Gestão Participativa.

\section{RESULTADOS}

\subsection{GESTÃO PARTICIPATIVA: DE QUE ESTAMOS FALANDO?}

No campus Serra, na prática a importância dada à participação na gestão apresenta ambiguidades que, longe de significarem um processo de diálogo entre os servidores e gestores para a formação de uma esfera pública, nos moldes da democracia deliberativa de Habermas (1995), como espaço de transparência e de aprendizado social, em geral, caminha tão somente em direção aos aspectos gerenciais de eficiência com vistas aos resultados institucionais e pessoais. Contudo, sem darem a devida importância para o processo de elaboração da política organizacional e para a construção do planejamento estratégico (ABRUCIO, 1997).

Para os TAE e chefias imediatas do campus Serra o significado do termo gestão participativa configura três tipos de participação: (1) como espaço para o êxito na resolução de problemas setoriais; (2) como espaço para o diálogo no nível de consulta; (3) e como lugar para construção coletiva por meio da discussão e entendimento.

Faria (2009) ressalta que a participação como espaço para êxito na resolução de problemas setoriais ou restrita ao local de trabalho, sem o envolvimento com os temas globais da organização, aproxima-se da participação consultiva, na medida em que o trabalhador é envolvido na operação das tarefas, e em alguns momentos pode ser chamado a opinar sobre as melhores maneiras de realizar as tarefas e dar sugestões de melhoria nos processos de controle 


\section{ABORDAGEM CRÍTICA SOB A ÓTICA DA AÇÃO COMUNICATIVA DE HABERMAS: GESTÃO \\ PARTICIPATIVA NO CAMPUS SERRA DO IFES \\ DOI: http://dx.doi.org/10.5007/1983-4535.2018v11n1p276}

do trabalho. De acordo com Faria (2009, p. 120), a participação restrita e consultiva "[...] constitui-se exclusivamente como ideologia do capital, como estratégia de dominação e controle e não como iniciativa do trabalhador".

Essa conceituação está associada à racionalidade instrumental onde prevalece apenas a perspectiva de um dos participantes (o agente da ação racional), sendo o outro considerado um meio para o êxito, sem a preocupação com a emancipação e a possibilidade do diálogo e do aprendizado coletivo. E nesse caso, considerando a linguagem como recurso indispensável à interação, a comunicação acaba por ser distorcida em razão dos fatores estruturais, característicos do contexto organizacional da Administração Pública, os quais mantêm contradições sistemáticas no processo de representatividade de interesses (VIZEU, 2003).

Assim, a participação perde o seu caráter político e de potencial transformador das assimetrias existentes nas relações (HABERMAS, 1997). A participação fica limitada ao alcance das metas da instituição e subjulgada aos imperativos sistêmicos.

$\mathrm{Na}$ fala dos TAE e chefias imediatas o diretor-geral deve permitir a participação e os servidores devem comprometer-se. Faria (2009) e Paes de Paula (2005) afirmam que essa é uma perspectiva gerencialista, na qual a participação é função do gestor, com foco na cooptação dos indivíduos, restando ao trabalhador o papel de executor das tarefas com vistas à alcançar resultados.

A participação não pode ser delegada e nem institucionalizada (STRECK; ADAMS, 2006). Desse modo, no âmbito democrático deliberativo a participação insere-se em níveis efetivos de comprometimento, numa participação mais intensa, comprometida com a transformação e não só com melhorias (BORDENAVE, 1994, p. 22). Ocorre a diluição de papéis e funções num espaço político, intersubjetivo, autônomo e constituído por atores em iguais condições de justificação, num contexto de interações simples denominado esfera pública (HABERMAS, 1997). Gestores e trabalhadores atuando como agentes políticos num debate onde as decisões coletivas não se restrinjam à uma minoria privilegiada.

No ambiente organizacional isso não significa a extinção das formas de gestão, mas inserção de maior transparência, flexibilidade e participação nos assuntos de interesse coletivo por meio do "reacoplamento" entre o sistema e o mundo da vida (AGUIAR, 2011; FREITAG, 1993). É a primazia da razão comunicativa sobre a razão instrumental, de maneira a alcançar tanto eficácia quanto a responsabilização dos participantes em relação às decisões tomadas (PINTO, 1994). 
$\mathrm{Na}$ fala de alguns TAE e chefias imediatas percebe-se um discurso avançado em relação à definição e importância da participação. A participação nessa perspectiva significa um lugar para construção coletiva por meio da discussão e entendimento, com visão sistêmica em iguais condições de argumentação e que se aproxima dos pressupostos defendidos por Habermas em sua Teoria da Ação Comunicativa:

Quando você tem todo mundo andando para um lado só, as pessoas entendem, mesmo que sua opinião seja voto vencido: ah, eu sou voto vencido, mas agora eu vou com o grupo, com a decisão que foi tomada. Isso é gestão participativa. Quando vai todo mundo no mesmo sentido (CHI-7).

Contudo, na prática, constatou-se que essas perspectivas de uma participação ativa e emancipadora estão longe da sua concretização no campus Serra, já que a formulação e controle de políticas de forma geral são pensados e articulados por um grupo estratégico. Aos TAE, principalmente àqueles que não possuem cargo de chefia, fica reservado o papel de espectador ou executor.

\subsection{PARTICIPAÇÃO E INTEGRAÇÃO: CADA UM VAI LÁ E DEFENDE O SEU!}

A integração setorial é em demasia problemática, pois não existe uma preocupação ou intenção de compartilhamento das informações de interesse coletivo, e isso não se restringe à gestão. Para os TAE, de maneira geral, a busca e o compartilhamento de informações ocorrem apenas de forma individualizada ou quando os interesses dos respectivos setores são impactados: "o que eu vejo é que funciona da seguinte forma: cada setor vai lá, junta a diretoria e defende o seu. É essa forma que eu vejo aqui. Tipo assim: ah, meu setor está precisando disso e disso! Vai lá direto na diretoria e faz isso" (TAE-1).

A participação intersetorial possibilita uma visão integrada das políticas da organização (AGUIAR, 2011). Na prática essa integração não vem ocorrendo, prevalecendo uma visão fragmentada, desarticulada e focada na busca por interesses individuais.

A busca por soluções a respeito de questões pontuais que vão impactar diretamente a rotina dos respectivos setores é uma constante nas ações comunicativas dos TAE e chefias imediatas. Sendo assim, ao serem questionados sobre a tomada de decisão em assuntos de interesse coletivo, os mesmos se perdem na reflexividade sobre essa prática. Não conseguem visualizar temas estratégicos que o Campus tem autonomia para tomar decisão e que poderiam, de alguma forma, ter a contribuição da coletividade. As respostas foram dadas de 
forma imprecisa, baseadas em opiniões próprias. Isso evidencia a falta de visão sistêmica marcada pela divisão entre os servidores que trabalham diretamente na área do ensino e os servidores lotados na área administrativa.

Aguiar (2011) destaca a importância da ação integradora como fator essencial para o alcance de melhores resultados na construção de políticas e assevera o desafio na efetivação, pois envolve decisão política e articulação entre gestores e demais profissionais de diversas áreas, integrando os diversos saberes e conhecimentos. Esse argumento vai ao encontro com a teoria de Habermas (2012, v. 2) na medida em que a TAC propõe a renovação do saber por meio do entendimento, a integração, a solidariedade e a socialização como princípios básicos do agir comunicativo.

A fala do TAE-2 leva à reflexão sobre as afirmações de Habermas (2012, v. 2) a respeito da diferenciação causada pelo sistema, expressa na "divisão do trabalho". Para Habermas, essa diferenciação não se restringe ao mundo do trabalho, é uma condição social estabelecida pelas relações entre o sistema e o mundo da vida. Mais uma vez é possível identificar como as estruturas institucionais expressas na forma de regras e procedimentos, também presentes também no âmago da sociedade, promove o que Habermas (2012, v. 2) chama de "socialização e integração social" que se sedimenta não no entendimento, mas "[...] sim nas estruturas simbólicas do si mesmo e da sociedade em competências e padrões de relacionamento" (HABERMAS, 2012, v. 2, p. 47).

Acho que tem uma diferença também assim na maneira como, talvez, a gente é visto. Quero dizer assim, as letrinhas. Essa política das letrinhas de ter o técnico de nível $\mathrm{C}$, de nível $\mathrm{D}$ e nível $\mathrm{E}$, isso também gera fragmentação, entendeu? [...] Por que aí se casa com a história da FG, se eu tenho uma FG melhora e aí você faz 6 horas e eu não faço, entendeu. Aí vai imbricando tudo isso e gera, talvez, assim essa relação que a gente tem hoje. Cada um tá dentro do seu setor, tá brigando pelo seu, né, e aí pensando num mundo de hoje, isso é ótimo, isso só mantém essa lógica de vida que a gente tá tendo aí (TAE-2).

A diferenciação entre servidores causada por questões estruturais (níveis, salário, gratificação etc.) leva a disputa pelo poder e ao atendimento individualizado. Somado a isso a falta de controle dos processos e do desempenho leva a informalidade, ao personalismo, a condução das relações de trabalho por relações de amizade e, portanto, a formação de grupos afins e a mais disputa pelo poder. Nesse caso, a diferenciação, expressa na fragmentação das relações, entre os TAEs ao mesmo tempo em que mantém a disputa individualizada pelo poder configura resultado dessa disputa. 


\subsection{LIMITES À PARTICIPAÇÃO}

Durante as entrevistas e na observação participante emergiram muitos fatores que limitam a participação mais ativa dos TAE, tanto nos canais institucionais de participação como o Conselho de Gestão e Planejamento Estratégico, quanto nas ações coletivas promovidas pelos próprios TAE. Entre os fatores, destacaram-se como limites à participação: o comodismo, desinteresse e medo (mea culpa); a descrença no processo; a falta de informação, a falta de conhecimento e falta de tempo; e a existência de uma Política centralizadora, a presença da razão instrumental na política e o "personalismo".

Alguns participantes alegaram que a falta de interesse generalizada em assumir compromisso ocorre em razão do acúmulo de trabalho. O gerencialismo ao possibilitar a implementação de práticas participativas de cunho instrumental nas organizações cria um impasse para uma verdadeira participação democrática, pois concentra um maior número de funções em um único funcionário fazendo surgir resistências à participação por parte dos trabalhadores (PAES DE PAULA, 2005). Nesse caso a participação significa "uma atribuição de novos cargos sem concessão proporcional de poder” (PAES DE PAULA, 2005, p. 92). Portanto, a busca pela participação, quando existe, é mobilizada pelo ganho individual.

Alguns TAE atribuíram ao medo de assumir posicionamentos diante de determinados assuntos como justificativa para omissão. Para os TAE e chefias imediatas, o medo de sofrer represália deve-se principalmente à reação dos colegas de trabalho, mais do que a própria gestão. De acordo com Pinto (1994) este medo não pode ser entendido apenas como ato de vontade do indivíduo, mas como consequência de um processo mais abrangente de colonização do mundo da vida pelos mecanismos dinheiro e poder. Paes de Paula (2005) ressalta ainda que a nova gestão pública traz um falso discurso de liberdade, pois o papel do administrador é substituído pelo controle e pressão dos colegas de trabalho.

Na administração pública, onde o dinheiro e o poder não podem forçar a solidariedade, senão pela domesticação (VIZEU, 2005), o uso dos atos perlocucionários se faz constante e quando conhecido compromete os fins, fazendo surgir o desinteresse pela participação tanto em assuntos de importância para a organização quanto em assuntos de interesse coletivo.

O desinteresse generalizado por parte dos servidores leva a gestão ou um núcleo estratrégico formado por servidores com capacidade e condições de articulação a gerir com autonomia e a ditar regras e normas à todas as esferas da organização. Esses argumentos aproximam das reflexões de Habermas (2012, v. 1 e 2) sobre as implicações da colonização 


\section{ABORDAGEM CRÍTICA SOB A ÓTICA DA AÇÃO COMUNICATIVA DE HABERMAS: GESTÃO \\ PARTICIPATIVA NO CAMPUS SERRA DO IFES \\ DOI: http://dx.doi.org/10.5007/1983-4535.2018v11n1p276}

do mundo da vida para a sociedade, onde o mundo da vida passa a ser coordenado por normas e regras estabelecidas pelo sistema.

A esse respeito Habermas $(2012$, v. 2, p. 60) ressalta que “[...] a regulação do agir mediante normas pode ser entendida como a solução do problema que se coloca quando uma linguagem de sinais já não consegue coordenar as ações". Ou seja, a regras e normas constituem alternativa à impossibilidade de diálogo e entendimento.

No âmbito do campus Serra, a apatia pela participação tem feito dos TAE um público de espectadores que veem o emprego público como uma dádiva, não como uma conquista com deveres e direitos. Conforme comenta Pinto (1994, p. 151), "dentro da lógica sistêmica cada um cumpre o seu papel, sem interferir na função alheia, e o sistema educacional anda por si mesmo".

No que se refere a descrença e desconfiança na gestão bem como nos mecanismos de participação instituído, essa limitação é resultado do processo de formulação de políticas e decisões estratégicas fundamentado nas velhas práticas patrimonialistas, centralistas e autoritárias de gestão. Essas constatações estão em consonância com os argumentos de Paes de Paula (2005), quando sinaliza a permanência dos vícios do patrimonialismo, clientelismo e outros "ismos" ao discutir os limites da nova administração pública brasileira.

Os TAE e chefias imediatas afirmam a descrença em participar por sentirem que não são ouvidos e por perceberem que a própria opinião não tem relevância para a gestão durante a tomada de decisão. Outro fator que tem levado à desconfiança estaria na questão das soluções serem apresentadas de maneira pré-definida pela gestão.

Habermas (1989, p. 79) ressalta que no agir comunicativo a base de motivação da participação é o "[...] efeito ilocucionário de comprometimento que a oferta de um ato de fala suscita [...]". Sendo assim, a motivação está associada à veracidade dos atos de fala empregados com vistas ao entendimento. Os servidores ao perceberem os jogos de interesses inclusos nos mecanismo ditos de participação afastam-se do processo ou participam de forma passiva apenas para cumprir as exigências conferidas ao cargo.

É nítida a falta de informação e conhecimento dos TAE e chefias imediatas a respeito dos assuntos estratégicos e da construção de políticas do campus Serra. Compreende-se que as informações e conhecimento estão restritos a área de atuação, naquilo que confere o cargo ou função. As informações estratégicas ficam restritas a um grupo específico e são compartilhadas de maneira superficial pelo email e site institucional. Sendo assim, o 
compartilhamento por meio do debate público não faz parte da rotina dos TAE: “[...] não existe movimento de: o que vocês pensam sobre isso pra gente levar? Até hoje não houve. Pode ser que aconteça" (TAE-7).

A informação e a capacidade de articulação dessa informação na forma de conhecimento são imprescindíveis para a consolidação e qualificação da democracia deliberativa nos moldes habermasianos. Sendo assim, a falta de informação diminui as possibilidades de argumentação e, por consequência, inibe os atores de expressarem suas pretensões de validade num processo democrático de formação da opinião e da vontade.

Ouro fator limitante à participação é a falta de tempo devido "carga" de trabalho diária. Essa justificativa foi citada ao afirmarem que as tarefas diárias são prioridade em detrimentos da participação em questões que não fazem parte do contexto interno dos respectivos setores.

Além disso, compreende-se que a prática da gestão participativa no campus Serra configura um espaço norteado por uma política centralizadora, pela sobreposição da razão instrumental na política e pelo personalismo.

A centralidade se restringe a um grupo específico, envolvido de forma constante nos assuntos estratégicos do Campus, revelada na forma de monopólio da informação e de outros mecanismos. Essa questão foi identificada com nitidez durante as reuniões para apresentação das propostas por parte da gestão sobre a implementação do curso técnico integrado no Campus. Os TAE entendem que esse tema foi levado para discussão como uma decisão préestabelecida, pensada por um grupo:

[...] eu ouvi que deu, assim, a impressão que me passaram né, que realmente a coisa já tinha vindo sendo construída. A gestão em nenhum momento falou com a gente sobre isso: olha, a gente tá pensando nisso, vai montar uma comissão. Não! (TAE-2).

A dificuldade no diálogo entre os servidores, seja na aceitação dos argumentos dos demais, seja na capacidade dos TAE de expor os próprios argumentos, demonstram que essa forma de fazer "política" está longe dos ideais propostos por Habermas em sua democracia deliberativa, a qual prioriza o debate, a reflexão e o uso do melhor argumento sobre a coerção.

Sob o discurso do ganho em eficiência, a nova administração pública incentiva o individualismo do decisor quando aumenta o poder discricionário dos burocratas, ampliando o incentivo às práticas personalistas e voluntaristas (PAES DE PAULA, 2005). Embora os TAE e chefias imediatas ressaltem o papel do gestor como tomador de decisão, o que se percebe é 


\section{ABORDAGEM CRÍTICA SOB A ÓTICA DA AÇÃO COMUNICATIVA DE HABERMAS: GESTÃO \\ PARTICIPATIVA NO CAMPUS SERRA DO IFES \\ DOI: http://dx.doi.org/10.5007/1983-4535.2018v11n1p276}

que no campus Serra a articulação do gestor submerge num círculo vicioso de atendimento à interesses com vistas à manutenção do cargo designado por via de eleição. Longe dos ideiais Habermasianos de mediador do debate entre os servidores, a atuação do gestor limita-se à articulação de interesses mediada pelo "perigo" que o não atendimento pode representar.

\subsection{A INSATISFAÇÃO COM A PRÁTICA DA GESTÃO PARTICIPATIVA}

Ficou evidente nas entrevistas dos TAE e chefias imediatas a insatisfação com a prática da gestão participativa no campus Serra. Entre os fatores que levam a insatisfação emergiram na fala dos participantes da pesquisa: a falta de transparência, a falta de sistematização dos processos de trabalho gerada pela informalidade e o imediatismo.

Em termos da falta de transparência os TAE afirmam que existem assuntos relativos à própria rotina que não são compartilhados pela gestão como a distribuição de verba para capacitação, distribuição de Função Gratificada (FG) entre os coordenadores e de servidores entre os setores.

Decisões estratégicas a respeito de projetos vultosos não são colocadas para discussão coletiva. Mesmo para aqueles que percebem a permanência de certo nível de discussão, existe o questionamento sobre a existência de assuntos que são de interesse da comunidade interna e que não são compartilhados. Isso por que a decisão sobre o que deve ser divulgado é tomada pela gestão.

Outro fator que tem motivado a insatisfação está relacionada à falta de mobilização por parte da gestão para os TAE participarem das reuniões e também a falta de divulgação das discussões e tomadas de decisão estabelecidas nas reuniões, o que tem comprometido a transparência do processo decisório. De forma geral, a compreensão de que não há transparência está associada a uma suposição de que é uma questão estratégica para evitar conflitos e manter os servidores alheios e passivos às decisões tomadas.

Para Freitag (1993) a ocultação dos interesses cria um impasse, pois a transparência representa um dos pilares para o reacoplamento entre o sistema e o mundo da vida, permitindo uma visão em conjunto com base na dialogicidade para a formação de uma esfera pública nos moldes da democracia deliberativa de Habermas (1995).

Para os TAE e chefias imediatas, a falta de sistematização nos processos de trabalho tem levado à informalidade e ao amadorismo em todos as ações de gestão. O que tem contribuído para a insatisfação com a prática da gestão participativa, pois os TAE não 
conseguem vislumbrar efetividade nas práticas de gestão participativa. Os TAE associam a informalidade e desorganização na forma de realização das atividades à inexistência do controle dos processos de trabalho pela gestão. O serviço prestado fica delegado à "própria sorte" da capacidade e comprometimento do TAE em executá-lo.

Habermas não descarta a existência da razão instrumental, apenas defende o papel secundário que essa deve assumir nas ações humanas em sociedade com base na transparência e no entendimento. A informalidade e "desorganização" dos processos de trabalho dificulta o acesso às informações, portanto, a formação do conhecimento sobre os assuntos essenciais que dizem respeito ao funcionamento da instituição e que podem servir de base para o diálogo. Além disso, a informalidade fomenta o surgimento de ações individualizadas e centralizadoras.

Para os TAE e chefias imediatas, as decisões são tomadas e o conhecimento somente é transferido ao setor impactado pela decisão no momento da execução. Esse modo de fazer uma gestão participativa com base na busca por soluções imediatas configura uma estratégia para cooptação do conhecimento e exploração dos trabalhadores (FARIA, 2009). Habermas (2012, v. 2), ao propor a racionalidade comunicativa supera a visão unilateral de racionalidade onde a participação está associada à maximização dos ganhos. Com a racionalidade comunicativa o trabalhador participa do processo decisório de forma corresponsável, e, sobretudo, com autonomia.

A possíbilidade de articulação e diálogo que existe no campus Serra não garante uma gestão participativa efetiva, pois a busca por soluções à "curto prazo" e de forma superficial desqualifica o processo participativo.

Então, articulação, o diálogo ele acontece né. Você chega com uma demanda, por exemplo, agora o problema, também, é essa articulação assim. Eu não percebo um entendimento real do problema que está acontecendo pra se pensar numa proposta que não seja paliativa. [...] Então, a articulação ela não acontece de forma efetiva assim. Só se faz coisas paliativas (TAE-3).

O imediatismo não reflete somente as ações da gestão, mas está presente na articulação e diálogo entre os TAE, os quais são coordenados pela necessidade imediata de resolução de questões relativas à rotina. 


\section{CONSIDERAÇÕES FINAIS}

Ao comparar a ação comunicativa dos sujeitos da pesquisa com as práticas específicas de gestão participativa no campus Serra pode-se observar que essas práticas constituem resultado e, ao mesmo tempo, "mola propulsora" do pensar e do agir comunicativo predominante. Desse modo, a prática da gestão participativa caracteriza-se como um espaço onde os sujeitos clamam por democracia quando não conseguem se fazer ouvir, mas quando há possibilidade de articulação coletiva os interesses pessoais ou setoriais são colocados como prioridade na tomada de decisão em detrimento do bem coletivo.

Conforme exposto nas seções anteriores, o cenário da gestão participativa no campus Serra apresenta contradições que, longe de significar um espaço de diálogo entre os servidores e gestores para a formação de uma esfera pública nos moldes da democracia deliberativa de Habermas (1995), configura, em predomínio, comprometimento com o desempenho e reforço do sistema capitalista, caracterizando-se como participação instrumental e não como forma de resistência aos mecanismos de controle e dominação (FARIA, 2009).

É nítido que o estado de apatia generalizada por parte dos TAE e chefias imediatas, transversal às oportunidades de participação na gestão, tem contribuído para a permanência da formulação de políticas e de planejamento no âmbito do núcleo estratégico da instituição. Essa apatia configura resultado do processo de colonização do mundo da vida pelos mecanismos dinheiro e poder, que conduz os trabalhadores a agirem de forma fragmentada, segundo os próprios interesses (HABERMAS, 1997).

À luz da Teoria da ação Comunicativa, o resultado desse processo de colonização do mundo da vida é a transformação dos trabalhadores em clientes, o aperfeiçoamento de uma cultura de especialistas e a destruição da reflexividade crítica dos TAE e chefias imediatas, os quais veem o emprego público como uma dádiva, não como uma conquista com deveres e direitos. Nesse cenário, cada qual assume o seu papel legalmente estabelecido sem questionar as formas de controle. Ao TAE, em geral, cabe o papel de se comprometer na busca pelos resultados da instituição e ao gestor de possibilitar a participação quando julgar necessário na forma de cooptação do conhecimento do trabalhador.

Vale ressaltar que não houve a pretensão nessa pesquisa de encontrar o modelo de Habermas expresso no agir e no entendimento dos sujeitos, haja vista o predomínio dos valores capitalistas em nossa sociedade, os quais fomentam ações individualistas e instrumentais, mas de explorar um referencial teórico que se propõe como alternativa ao 
modelo hegemônico. Nesse sentido, a Teoria da Ação Comunicativa é apresentada enquanto utopia, não como algo irreal, mas idealizável, como um processo, uma tentativa sem fim de superação do modo de exploração capitalista.

Portanto, Habermas (2012, v.1 e 2) não desconsidera a razão instrumental, nesse caso expressa na forma de ferramentas gerenciais, mas afirma que a razão instrumental deve estar subjulgada à razão comunicativa num processo dialógico. Ou seja, a construção e implementação das ideias e práticas gerenciais devem ser efetivadas com base no diálogo e no entendimento.

Para que a instituição de fato comece a caminhar em direção à participação democrática é necessária uma mudança na forma de pensar a participação. Sendo assim, dada a variedade conceitual em torno do tema participação, é importante estimular o debate sobre as possibilidades participativas a fim de se esclarecer o significado democrático. Além disso, promover discussões de cunho pedagógico de aprendizado sobre as formas dos trabalhadores se inserirem e influenciarem na construção de políticas e no planejamento da instituição.

Sobretudo, o estudo das práticas de gestão participativa revelou contradições existentes no funcionamento dos canais participativos e nas próprias relações cotidianas dos TAEs. Perceber-se que, dado o sentido amplo do tema "prática da gestão participativa", a necessidade de estudos futuros na instituição estudada visando compreender de maneira mais aprofundada essas contradições. Nesse cenário, vale ressaltar a internalização dos valores sistêmicos por parte dos sujeitos da pesquisa, os quais acreditam que a solução para a participação democrática esteja no aperfeiçoamento das ferramentas gerenciais, enquanto mecanismos de controle e dominação. É pertinente compreender como essa dinâmica sistêmica é introjetada nos indivíduos, de maneira que esses não conseguem enxergar formas alternativas, além do aperfeiçoamento das já existentes, que podem levar à emancipação de fato.

Embora a prática da gestão participativa no campus Serra esteja distante do modelo habermasiano de democracia deliberativa e o papel do trabalhador seja reduzido a um cliente, acredita-se na possibilidade de existir nesse domínio organizacional a vinculação entre a administração e a política. O viés participativo presente na elaboração das políticas e ações e ainda a pré-disposição à participação dos TAE e chefias imediatas revelada durante as entrevistas e na observação participante precisam ser melhor exploradas num espaço organizado de forma autônoma com base no debate coletivo sobre temas relevantes. 


\section{REFERÊNCIAS}

ABRUCIO, F. L. O impacto do modelo gerencial na administração pública: um breve estudo sobre a experiência internacional recente. São Paulo: Enap. 1997.

AGUIAR, M. M. Gestão de serviços de abastecimento de água e esgotamento sanitário: a Participação Social em Três Modelos. 2011. 338 f. Tese (Doutorado em Saneamento, Meio Ambiente e Recursos Hídricos) - Programa de Pós-Graduação em Saneamento, Meio

Ambiente e Recursos Hídricos, Universidade Federal de Minas Gerais, Belo Horizonte, 2011.

AUSTIN, J. L. Cómo hacer cosas con palabras. Buenos Aires: Paidós, 1995.

BALDIN, N.; MUNHOZ, E. M. Snowball (Bola de Neve): uma técnica metodológica para pesquisa em educação ambiental comunitária. In: Seminário Internacional de representações sociais, subjetividade e educação, 1., 2011, Curitiba. Anais... Curitiba: EDUCERE, 2011.

BARDIN, L. Análise de conteúdo. São Paulo: Edições 70, 2011.

BORDENAVE, J. E. D. O que é participação. Coleção Primeiros Passos. 8. ed. São Paulo: Brasiliense, 1994.

BRASIL. Lei $\mathrm{n}^{0}$ 8.112, de 11 de dezembro de 1990. Dispõe sobre o regime jurídico dos servidores públicos civis da União, das autarquias e das fundações públicas federais. Diário Oficial [da] República Federativa do Brasil, Brasília, DF, 12 de dezembro de 1990. Disponível em: < http://www.planalto.gov.br/ccivil_03/leis/19501969/L3780.htm>. Acesso em: 13 mar. 2014.

. Lei n ${ }^{\circ} 11.892$, de 29 de dezembro de 2008. Institui a Rede Federal de Educação Profissional, Científica e Tecnológica, cria os Institutos Federais de Educação, Ciência e Tecnologia, e dá outras providências. Diário Oficial [da] República Federativa do Brasil, Brasília, DF, 29 de dez. de 2008. Disponível em:

$<$ http://www.planalto.gov.br/ccivil_03/_ato2007-2010/2008/lei/111892.htm>. Acesso em 07 maio 2014.

DEMO, Pedro. Participação é conquista: noções de política social participativa. 2. ed. São Paulo: Cortez, 1993.

DESLANDES, S. F. O projeto de pesquisa como exercício científico e artesanato intelectual. In: MINAYO, M. C. S. (Org.) Pesquisa social: teoria, método e criatividade. 19. ed. Petrópolis: Vozes, p. 43-49, 2007.

FARIA, J. H. Gestão participativa: relações de poder e de trabalho nas organizações. São Paulo: Atlas, 2009.

FREITAG, B. A teoria crítica, ontem e hoje. São Paulo: Editora Brasiliense, 1990. 
.Habermas e a filosofia da modernidade. Perspectivas: Revista de ciências sociais, Ceará, v. 16, n. 1, 1993.

HABERMAS, J. Teoria de la acción comunicativa: crítica de la Razón funcionalista. Tradución. Manuel Jiménez Redondo. Madrid: Taurus, 1987. v. 2, 512p. 1989. $233 \mathrm{p}$

Consciência moral e agir comunicativo. 2. ed. Rio de Janeiro: Tempo Brasileiro,

O entrelaçamento de mito e esclarecimento: Horkheimer e Adorno. In: $\mathbf{O}$

discurso filosófico da modernidade: doze lições. Tradução de Luiz S. Repa e Rodnei Nascimento. São Paulo: Martins Fontes, 1990. p. 153-186.

. Três modelos normativos de democracia. Lua nova revista de cultura e política, São Paulo, n. 36, p. 39-53, 1995.

O Processo Democráticos e o Problema de sua Neutralidade. In: Direito e democracia: Entre facticidade e validade. Volume II. Rio de Janeiro: Tempo Brasileiro, p. 25-41, 1997.

O conceito de "esfera pública". In: Direito e democracia: Entre facticidade e validade. Volume II. Rio de Janeiro: Tempo Brasileiro, p. 92-98, 1997.

Agir comunicativo e razão destranscendentalizada. Rio de Janeiro: Tempo Brasileiro, 2002.

.Teoria do Agir comunicativo: Racionalidade da ação e racionalização social. Tradução: Paulo Astor Soethe. São Paulo: WMF Martins Fontes, p. 19-131. 2012. v. 1.

.Teoria do Agir comunicativo: crítica a razão funcionalista. Tradução: Paulo Astor Soethe. São Paulo: WMF Martins Fontes, 2012. v. 2.

MINAYO, M. C. S. Trabalho de campo: contexto de observação, interação e descoberta. In: __ Pesquisa social: teoria, método e criatividade. 19. ed. Petrópolis: Vozes, p. 62-68, 2007.

MOTTA, F. C. P. A co-gestão alemã: as Conciliações do Inconciliável. RAE-Revista de administração de empresas, São Paulo: v. 23, n. 1, jan-mar, 1983.

PAES DE PAULA, A. P. Por uma nova gestão pública: limites e potencialidades da experiência contemporânea. Rio de Janeiro: Editora FGV, 2005.

PINTO, J. M. de R. Administração e liberdade: um estudo do conselho de escola à luz da teoria da ação comunicativa de Jürgen Habermas. Rio de Janeiro: Tempo Brasileiro, 1994. $184 \mathrm{p}$. 
PINTO, J. M. de R. A teoria da ação comunicativa de Jürgen Habermas: conceitos básicos e possibilidades de aplicação à administração escolar. Paideia (Ribeirão Preto), Ribeirão Preto, n 8-9, aug. 1995.

STRECK, D. R.; ADAMS, T. Lugares da participação e formação da cidadania. CivitasRevista da Ciências Sociais. São Paulo: FFCH-PUCRS, v. 6, n. 1, 2006.

TRIVIÑOS, A. N. S. Introdução à pesquisa em ciências sociais: a pesquisa qualitativa em educação. São Paulo: Atlas, 1987. cap. 5, p. 116-174.

VIZEU, F. Algumas contribuições da teoria da ação comunicativa para a área de organizações. XXVII EnANPAD, Atibaia, 2003.

Ação comunicativa e estudos organizacionais. RAE-Revista de administração de empresas, v. 45, n. 4, p. 10-21, 2005. 